Revista cla ANPOIL, n" 5, p. 65-76, jul/dde\%., 1998

\title{
UMA BARCAROLA DE AUGUSTO DOS ANJOS
}

Chico Viana*

HESUMO: A lxurcurola ou marinha, compessiggios lírias medienvil, é uma uxariante cla cantiga de amigo em que mogu do powo se dirige às ondas a fim de lamentar a cusência do amado, ou perdir-lhes notícias dele. O propiósilo deste arligo é ler a Ixurcarola compossta por Augusto dos Anjoss (1SS4-1912) e posteriormente publioncka em seu túnico livro, Eu. Em nosss leilura teceremos, inicialmente, breves considerrıçōes históricas sobre essa espécie mediersul e set deschobrramento na lírica moderna; a segaii; apreciaremoss a particular configarraçäo que lal espécie adquire numa poética como a de Alugisto des Anjos, marcada pelo sentimento de culpxi, pelo prossaísmo e pela mortidez.

PALAVIRAS-CHIIVE: medievalismo e poesia moderna; omralidade na pxorsia; literuturre e melancolist.

$\int 4$

nosso propósito neste artigo ler o pocma "Barcarola", de Augusto dos Anjos, inscrido pelo pocta cm scu livro $E u$, postcriormente transformado $\mathrm{cm}$ Liu e outras poesias. Ciomo o título dessc poema alude a uma espécic ou subgênero cultivado pcla pocsia medicval, vamos de início tecer; a respeito, breves consideraçōes de ordem formal c histórica.

A barcarola foi praticada por alguns trovadores galego-porlugueses, entrc os quais mencionam-sc os nomes de Martim Codax, Comes Charinho c Joham Zorro.' Scgundo Scgismundo Spina², a pocsia luso-galcga nos legou, ao todo, quinzc barcarolas, sendo que treze delas apresentam cstrutura paralclística.'Também conhecida por marinha, cssc tipo de composição versa sobrc assuntos ligados ao rio ou ao mar - c isto tem a sua sua justificativa:

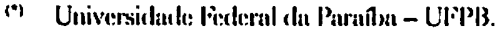

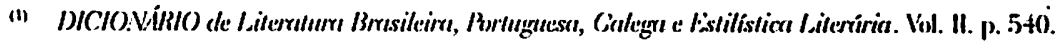

(t) In: 1 lirica Imotrodenesca. p. 36.5.
} 
VWNI, Chico. Uma barcarola de Augasto dess Anjos.

Num povo como o de Portugal e Caliza, em sua grande parte, nado e criado à beira-mar, este devia inspirar-lhe atrativo especial; o espetáculo diário das suas águas, ora tranquiilas c romansosas, ora agitadas c bravias, por força o levaria a compará-lo ao seu coraçño, que do mesno modo umas vezes pulsava sossegadanente, outras se agilava sob o influxo de fortes paixiōis. ${ }^{3}$

Esssa alternância de impressões c sentimentos reflctc-sc nos temas das cantigas, que variam pouco. Vendo nas águas um reflexo de suas tristezas c inquictaçōes, a mulher - que nas cantigas de amigo, como se sabc, fala pelo trovador - toma-as como confidentes c lamenta a demora do amantc, que ainda não voltou do scrviço militar. Ou lhes pede notícias do amado ausente. Noutras vezcs, cspera a cmbarcação que o trará de volta ou "...diz que scu 'amigo' (...), sc soubessc que cla ia banhar-se no rio, far-lhe-ia companhia."”.

É possível também que, em vez de sc dirigir às águas, a mulher sc dirija à mãc ou à irmã, cxortando-as a olhar o mar c, nclc, a "vcr" o amigo que sc foi. Numa das cantigas de Martim Codax (CV 886), é para cssas figuras, alternativamente, que se dirigc o apclo do eu lírico, conforme demonstra o fragmento a scguir: "Mia irmã fremosa, trcides de grado/ a la igrcja de Vig', u ć o mar lcvado; c mircmo'-las ondas. //A la igrcja de Vig',u ć o mar salido,/ c verrá i, madrc, o meu amigo:/ c mircmo'-las ondas." Nelc, chama-nos a atenção a expressividade do cstribilho: "c mircmo'-las ondas", que se repetc quatro vezes. O contínuo movimento das ondas, imagem do que continuamente sc constitui c se desfaz, accntua a ilusão, a aflita csperança com que a mulher "prescntifica" o amante.

Não deixa de haver; ncssc processo de identificação ou substituição, um cnlacc metonímico: foram as ondas que levaram o scu amigo - são clas que o vão trazcr: Assim, as ondas com cle se confundem.

Modernamente, chama-sc barcarola "todo poema de caráter sentimental c melodioso, relacionado com o mar,...". Ou nem isto. Em nossa

\footnotetext{
(3) NUNI:S, Jesé Jouspuim. Cantignas de amigon dos tmoxedores galego-portugnuses. p. 25.

(1) MOISlís, Massiunl. Dicioncirio de lermos lituririos. p. 56.

(5) Ilem. p. 57 .
} 
pesquisa sobrc os precursorcs medievais da pocsia moderna, deparamonos com pelo menos um pocma assim intitulado - "Barcarola" -, composto por Vinícius de Moracs, no qual o mar; ou qualquer referência a "água", cstá auscntc. Mas ć uma excção. No gcral, na pocsia do Romantismo para cá, a cssc termo sc associam cvocaçõcs, sugestõcs, pinturas de alguma forma ligadas ao clemento marinho.

Fintre os que cultivaram modernamente a barcarola, destacamsc, além do autor objeto deste artigo, os nomes de Almcida Carrett, Castro Alves, Alphonsus Cuimaracns c Olegário Mariano. Nas composiçõcs desses autores, a referência ao mar aparece - mas, obviamente, com scntidos, usos c cfeitos distintos. Nos cantares medicvais, por ser um clemento pragmaticamente associado ao sofrimento da mulher; a quem levou o amigo ausente, o mar tem um emprego, por assim dizer; mais concreto. Scgundo frisamos há pouco, cle sc constitui antes $\mathrm{cm}$ metonímia do que cm metáfora. Na medida $\mathrm{cm}$ que se desfaz como referente gcográfico c histórico, o mar crescc $\mathrm{cm}$ ressonâncias significativas, amoldando-sc ao imaginário, aos idcais c à retórica dos diferentes estilos de ćpoca.

Assim é que cm Castro Alves", na barcarola intitulada "O gondolciro do amor", o mar de início cmpresta alguns dos scus atributos ao corpo da mulher: "Técus olhos (...)/ São ardentes, são profundos,/ Ciomo o ncgrume do mar;". Postcriormente, aparece como uma imagem desse mesmo corpo, com o qual se cquaciona, lingüisticamentc, através do verbo de ligação: "lè scio ć vaga dourada/Ao tíbio clarão da lua,...". Lxplica-sc cntão a referência do título: enquanto gondoleiro, o eu lírico singra metaforicamente o corpo da mulher; com os scus prazcres e mistérios. Ou melhor; com as suas alternâncias de luminosidade c cscurcza, tempestade c calmaria, conforme refere o pocma.

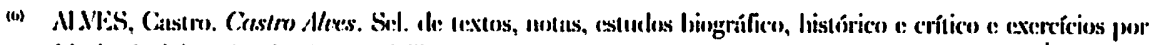
Marisa l ajolo e: Samira Caunpurdelli. p. 20. 


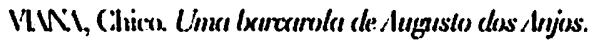

Em Alphonsus de Cuimaracns?, como não poderia deixa de ser; a alusão marinha tem ressonâncias quase místicas. $O$ que se tematiza não é mais a relação "homem c mulher", c sim um sublimado conúbio entre a lua c um parcciro que não sc definc. Desmatcrializado, o mar não mais vale por suas águas, por sua grandeza imanente; cle é tão-só o espelho, a trilha que reflete o movimento do luar no céu; é antes símbolo do que metonímia ou metáfora. Ém certa cstrofe, o eu lírico indaga: "Para onde vai a deusa crrante/ Maccrada, chcia de mágoas?/ Sacode a cabclcira ondcante/ E esparzc lírios sobrc as águas.". E na cstrofe scguintc afirma, através inclusive da correspondência cromática, a transcendência do clemento marinho: "O céu ć intciramentc azul,/O mar está da mesma cor.".

Quc dizer da representação do mar na barcarola de um autor como Augusto dos Anjos? Assim como os dois poctas citados, cle cultiva cssa espécic literária adaptando-a ao scu artesanato c ao seu temperamento. Por via disto, $\mathrm{cm}$ sua composição, a delicadeza nostálgica dá lugar à angústia rude, dramática c concreta diante da morte. Vejamos o poema, que se encontra na página 297 da Obra Completa do autor; organizada pelo pocta e crítico Alcxei Bueno".

\section{Barcarola}

\begin{tabular}{|c|c|}
\hline (antam natutas, cluoram flautus & Ouyam do allo a l tua Cheia \\
\hline Pelo mar e: pelo mals & Que a sercia vai falar... \\
\hline Una streia a cantar & I laja silêncio no mar \\
\hline Vela o Destinu dors nautats & Para se: ouvir a stercial. \\
\hline Espellham-se: ces esplendores & Que é que cla dlix?! Será umı \\
\hline Do céu, en) reflexes, nas & I listória de amor freliz? \\
\hline Águas, fingindo cristais & Nüo! O quu: a sercia diz \\
\hline Das mais desilumbrantes cores & Nāo é história nenhuma. \\
\hline
\end{tabular}

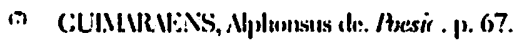

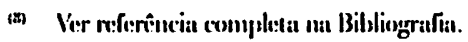


VLWI, (hico. Uma Ixarcarola de Alugasto dos dryos.

privilegiou em sua obra, composta basicamente de sonetos c de peças longas, o verso decassilábico. Ao praticar uma forma (ou fôrma) antiga, ligada ao Medicvo, certamente cle procurou se inserir na tradição da lírica galego-portuguesa, optando por um metro popular: Sabe-se que o verso redondilho maior "cra c ć, por excelência, o metro da pocsia popular hispânica. Daí o scu largo uso nas cantigas de amigo c de cscánio..."', bcm como nos romances antigos $\mathrm{c}$ modernos.

A barcarola que ora cstudamos compōc-sc de dezoito quadras, scndo que a última repete a primcira. Num total de 72 versos, após a descrição de um cenário sombrio (cstrofes 1 a 4), scguida de filosóficas considerações sobrc o sentido da aventura humana (estrs. 5 a 7), Augusto dos Anjos tematiza o cncontro cntrc o "pocta" c a screia (estrs. 8 a 15). Nessc encontro, o "pocta" não fala, só ouvc. E o que cle ouve, além da vecmente censura ao scu idealismo c às suas ilusōes de glória, é um sombrio vaticínio accrca do futuro que o espera, bem como a intimação a que sc conformc c saiba, à mancira de Cristo, morrer pelos homens. As estrofes finais (16 c 17), antes de fechar-sc o poema, referem a morte do "pocta" - o que nos dá a impressão, logo confirmada, de que a "scrcia" representa o destino.

Do ponto de vista estruturạl, essa barcarola decalca outro poema do paraibano - "As Cismas do Destino". 'Também neste ocorrem a pintura de um cenário, reflexõcs sobre o sentido da vida humana e, antes do desfecho, a manifestação de uma voz suprema c funda, carregada de presságios, a qual abomina a figura do "pocta" c lhe prevê a mortc. O eu lírico definc-a, cxplicitamente, como "o cco particular do (scu) Destino"(218)". Fis uma pequena amostra do que cle reverbera: "Pocta, feto malsão, criado com os sucos/ De um lcitc mau, carnívoro asqueroso, (...)// 'leu pé mata a uberdade dos caminhos/ It esteriliza os ventres geradores!" (221).

(n) DICIONÍRIO d!e Literatura... p. 5+3.

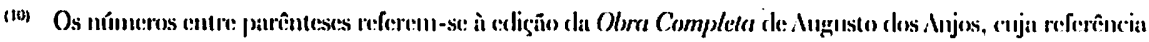
completa se: cencontra na Bibliografia. 
li en fulvos filōes doirados

Cai a luz dos astors por

Sobre o maritino horror

(cono globos cstrelaclos.

I í onde: als medhas so: assentam.

Fulyuram conno outros sóis

Os llanívonos farcóis

Qute os naveganntes oritentam.

Vai uma onda, rem outra onda

li nesse ecerno vaivém

Coitadas! não acham quem,

Quem ats esconda, as siconda...

Negoria tristonlan

Do que pelo menclo vini!

S: unl sonlat, outro se engne c cai;

Si: um cai, outro se cergut: so sonhan.

Mas desgracande do pooloro:

Que em meio da Víta cai!

Essse não volta, kist: vai

Para o túmulo que o colbre.

Vagueia um pos:ta unum barcos.

O) (ín, de cinna, a lurair

(amo um diamante de: Orir

Imila a c:urva do: am arro.

A 1.na - globo de: longa -

Simyiu, em lúcicto víu.

Cantam! Os atstors cko (áu

Ouçam e a I Aa C.luia ouģa! lí conoso un réquicem profundo

De tristíssimus benúis...

Sua vor ć igual à vor.

Dats doress toxlats do mundo.

"Ficclata-te: messe: nuedonloo

-Redulo de: Maldliçäo,

"Vájeiors da lixtrema-Ungão,

"Sonhlador do ćltimo sonhlon!

"Nima redona ilusíria

-Cercou-te a glória falizy,

"Mas nunca mais, nunca mais

"I lá de cencar-te csisa glória!

"Nunca mais! Sté, portim, forte.

*) pre:ta é como Jesust

: Vrragga-to: à tua (irus.

"í, nworve, pos:ta da Mlorte!"

- Fi disse e porryue: isto disse:

O luar no ('x́u sx: apagou...

Síbito o barno tomileus

Sem que o pre:ta o pressentisse!

Vistia de: luto o Univensoso

F: Deus se: cmlute mo (iéu!

Mais umu pen:ta que: nurrexu,

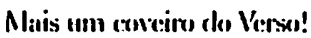

Cantam natutas, clummu fantulas

Polo mar e: pelo miarr

Uma scrvia n cantar

Vela o Destiun dess nautas?

O que primciro nos chama a atenção é que se trata de um dos raros pocmas de Augusto dos Anjos composto cm redondilha maior: O pocta 
Revista da INPOLLL, n" 5, p. 65-76, jul./de\%, 1998

Ėm outro estudo sobre o pocta", tentamos mostrar que cssc cxagcro autoacusatório, cssa profunda perda de auto-estima, refletc o menosprezo que o mclancólico tem por si. Ėm constante luto, cle transfere a si mesmo as recriminações originalmente cndereçadas ao objeto perdido, com o qual vcio a sc identificar: Também projeção da consciência culpada é o descjo de se sacrificar à mancira de Cristo, prescnte tanto nas "Cismas do Destino" quanto no pocma cm cstudo (vv. 57 a 60). lim várias passagens da pocsia de Augusto dos Anjos, por sinal, ć visível a obsessão de se identificar com Jesus c, assumindo a dor de todos os homens, redimir a humanidade.

Lcndo o poema do paraibano, uma referência de ordem intertextual sc impõc: a que o aproxima da famosa composição de Carrett, "Barca Bcla", também uma barcarola. Em ambos ocorre o motivo do canto da sereia, que por sinal remonta ao CantoXII da Odisséia. No texto de Homero cantam "as scrcias", no plural, mas o propósito dessas entidades mitológicas ć o mesmo que no de Carrett: seduzir; cnfeitiçar os navegantes, levando-os à mortc.

Em ambas as composiçõcs, do mesmo modo, obscrva-sc o cmprego do verbo "vclar". Na scgunda cstrofe de "Barca Bcla", lê-sc: "Não vês que a última cstrcla/ No cću nublado sc vcla?/ Colle a vcla/Ó pescador!", onde, num sutil jogo retórico, à terccira pessoa do singular desse verbo (vclar) scguc-sc o seu homônimo perfeito, designativo do artefato que estendiclo, c pcla força do vento, impulsiona a cmbarcação no mar: lim Augusto dos Anjos, logo na primcira cstrofe, cstá cscrito que "Uma scrcia a cantar/ Vcla o Destino dos nautas." - c, ncle, o cmprego desse verbo torna-sc mais cxpressivo devido à ambigüiidade. A screia tanto csconde, obscurcce (scntido que o termo tem cm Carrett), quanto vigia c acompanha os navcgadores. Ou scja: tem, cm comum com o destino, o mistćrio c a incxorabilidade.

Comentando o pocma do portuguĉs, Wolfgang Kayser obscrva que "...A screia é um ser concreto no mundo da pocsia, mas ć também a

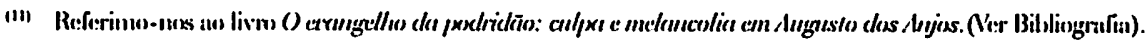




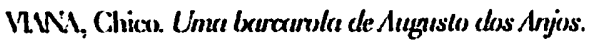

concretização dos perigos que cspcram o pescador no mar:" "'? Sc sc conccbe a travessia marítima como uma alcgoria do percurso do homem na 'Terra, é possível entender csses perigos como sendo, sobretudo, de natureza instintual. Ou scja: ligados à sedução do descjo. (O pocma encoraja a primeira interpretação, diga-se de passagem, ao referir que o vaivém das ondas - imagem sobrc a qual voltaremos a falar - ć uma "Alcgoria tristonha/ Do que pelo mundo vai!" - vv. 21,22). Em breve cnsaio sobre a mclancolia de Ulisses, o qual cnfoca o mencionado Canto XII da Odissćia, Olgária Matos sugere que "... As scrcias simbolizam muito do que nas mulheres é atracntc c terrível para os homens." ${ }^{\prime 3}$. O que se teme nclas, então, ć o irresistível apelo crótico - armadilha com que, enquanto objetos de descjo, clas buscam enredar c subjugar o sujcito; "...as scrcias são o passaclo c a tentaçāo de retorno a clc. Prometem plenitude $\mathrm{c}$ felicidade, mas ancaçam a autonomia do sujcito."

Essa idéia de cnredamento c subjugação cvidencia-se no poema de Carrett, onde o eu lírico acaba cxortando, descsperadamente, o pescador a fugir do canto perigoso c fatal: "Dcita o lanço com cautcla/ Quc a scrcia canta belca.../Mas cautela, / Ó pescador!// Não se enrede a rede ncla/ Que perdido é remo c vela/ Só de vê-la, / Ó pescador!// Pescador da barca bcla/ inda ć tempo, foge de cla./ Foge de cla/Ó pescador!" "is. Lim Augusto dos Anjos, o motivo crótico latente transplanta-se $\mathrm{cm}$ perspectiva fúncbre. O sensualismo, cm dor: A voz da sedução, na invectiva amcaçadora do destino. E o que ć o destino? Invocá-lo c temê-lo é reconhecer e reafirmar a culpa. Scgundo obscrva lreud ${ }^{16}$, o destino é a última entidade, na séric iniciada com os pais, que traduz o poder cerceador do superego. Confun-

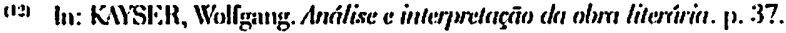

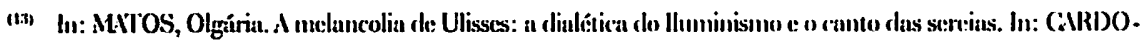
SO, Sérgio el alii. Os sentidess da pxitixion. p. 14).

(11) Item, ibidem. p. $1+6$.

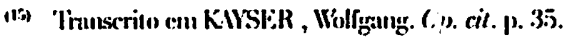

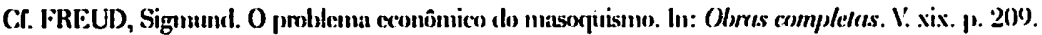


dido com o destino, o canto da scrcia "não é uma história de amor feliz" (v. 42); ao invés de maravilhar ou seduzir; cle "...É como um réquiem profundo/ De tristíssimos bemois.../ Sua voz é igual à voz/ Das dores todas do mundo." (vv. 45-48). Afirmando que o canto da sereia "não é uma história de amor feliz" (grifo nosso), o poeta não deixa de reconhecer nelc a promessa de satisfação amorosa. No entanto, nega esse reconhecimento ou melhor: denega-o, no sentido psicanalítico, só permitindo que ele se expresse sob a forma negativa. "Por meio do símbolo da negação", conforme observa Freud, "o pensamento liberta-se das limitações do recalcamento..."1?.

O eu lírico ignora ou finge ignorar o apelo da sereia, porque é próprio do melancólico defender-se do erotismo e preferir Tanatos. Configurando o campo semântico da morte, constam no poema em estudo as referências à cor negra, presentes sobretudo nas últimas estrofes: "O luar no Céu se apagou...", "Vista de luto o Universo"; as perífrases com que a sercia designa o "pocta": "Viajciro da Extrema-Unção", "Sonhador do último sonho", "pocta da Morte" c "coveiro do Verso"; e todo um acervo lexical ligado à idéia de desastre, cemitério e misćria: "horror; tristonha, desgraçado, túmulo, silêncio, tombou, luto etc.". As palavras da sercia constituem o limite a partir do qual o cenário alegoricamente se inverte, ou seja, deixa de figurar o brilho e o esplendor cromático e passa a traduzir a cscuridão c a ruína. É próprio da alegoria, figura essencialmente ligada à melancolia c à culpa, representar a natureza como escombros c escuridão. Antes de falar a sercia, a lua espelhava os scus raios nas águas, "fingindo cristais"; depois do sombrio vaticínio, "o luar no Céu se apagou" c, simbolizando um infortúnio supremo, o Universo "(vestiu-se) de luto".

Ainda no plano lexical, evidencia-se nessa barcarola a preferência por vocábulos preciosos ou cruditos, reflexo da influência que, sobretudo na primeira fase do pocta, cxerceu o Simbolismo. São exemplos desses

m Apud IAPIANCIIE E PONTALIS. Vocalutario de psicanailise. p. 295. 
VIANA, Chico. Uma barcarola de Augusto dos Anjos.

termos: "nautas, cristais, fulvos, flamívomos, Ofir; réquiem, viajeiro etc". Quanto à estrutura, registra-se outro recurso que é característico de Augusto dos Anjos: o de alternar elementos descritivos com genéricas considerações de ordem filosófica - atitude essa, por sinal, também típica do melancólico, que se compraz em observar, em refletir sobre os homens c as coisas. Nas estrofes V e VI, por exemplo, é o elemento natural, animizado, que serve de imagem à reflexão sobre o destino humano: "Vai uma onda, vem outra onda/ E nesse eterno vaivém/ Coitadas! não acham quem, /Quem as esconda, as esconda...// Alegoria tristonha/ Do que pelo mundo vai!/ Sc um sonha e se ergue, outro cai;/ Se um cai, outro se ergue e sonha.".

Também se percebe, no poema em estudo, outro dos traços estilísticos caros ao poeta, que é o de repetir vocábulos e expressões - scja na mesma ordem, seja na ordem inversa. Disso resulta um curioso efeito arquitetônico, o qual parece repercutir no ritmo. O discurso avança aos poucos, acumuladamente, retomando e dispondo em novos espaços os termos já referidos. Às vezes essas reiterações têm o propósito de, mediante as diferentes localizações das "formas de palavras", reiterar concretamente, em termos de espaço, o sentido. Noutras vezes a intenção é enfática, ou lúdica, ou musical como no verso "Quem as esconda, as esconda...". Vejamos outros exemplos: logo no início da composição, repete-se o adjunto adverbial de lugar "pelo mar"; a repetição da palavra "onda", em "vai uma onda, vem outra onda" (v. 17), sugere o "vaivém" expresso na linha seguinte, o movimento alternado c contínuo das vagas no mar; a construção $\mathrm{cm}$ quiasmo dos versos 23 e 24 ("Se um sonha e se ergue, outro cai;/ Se um cai, outro se crgue c sonha."), além de configurar intenção análoga à do exemplo anterior; constitui-se cm amostragem do ludismo ou, poderíamos mesmo dizer, do barroquismo do poeta.

Destacamos por fim os recursos ligados ao estrato fônico, um dos mais explorados por Augusto dos Anjos. São conhecidas as suas aliterações, assonâncias, sístoles e sinéreses, com as quais o poeta, bem expressionisticamente, tensiona e dificulta a emissão vocabular. Um pequeno exemplo 
disto se encontra nos últimos versos citados; ricos em aliteraçōes (da sibilante surda) e em sinćreses, cles parecem transbordar do metro heptassilábico. Dignos de nota, também, são os enjambements presentes nos sexto c nono versos, $\mathrm{cm}$ função dos quais o pocta rima preposição, ou forma contraída de preposição mais artigo, com substantivo ("por" com "horror" c "nas" com "cristais", respectivamente).

A título de conclusão, reiteramos o que quisemos demonstrar com o presente trabalho, ou scja: que não somente de ruptura $\mathrm{c}$ dissonância vive a pocsia moderna. A literatura se fáz, pelo diálogo entre modernidade e tradição, e se renova persistindo. Não ć raro que autores contemporâncos resgatem formas c modelos antigos, enriquecendo-os com novos temas, novos procedimentos artesanais e, sobretudo, com novos matizes de sensibilidade - conforme demonstra o aproveitamento de uma espécie medicval pelo "poeta da morte e da melancolia".

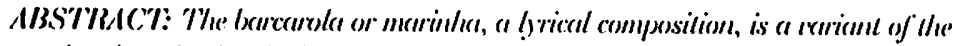

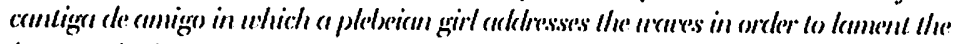

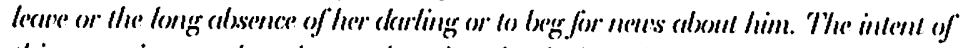

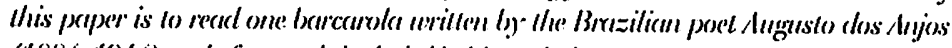

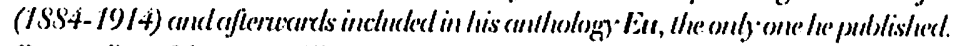

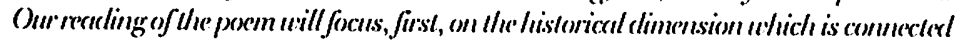

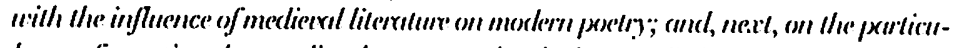

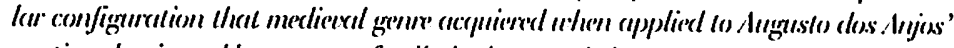

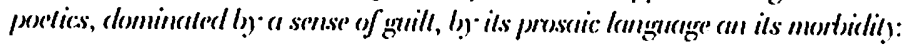

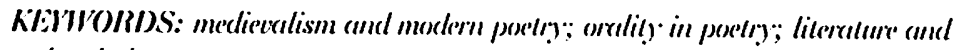
moluscholy:

\title{
BIBLIOGRAFIA
}

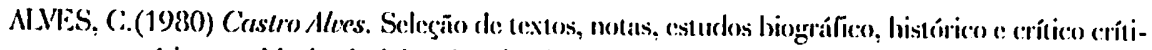

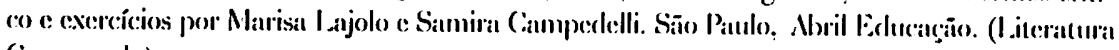
(iomentarla). 
VuW, (hico. Uma lxurcorrolo de Alugusto clos Anjos.

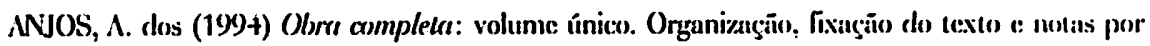
Nexci Bueno. Rio de Janciro, lmango.

DICIONÁRIO de L iteratura Brasileira, Portugutesa, Callega e Estilistica I iterária. Vol. II. (1978) Dir: Jacinto do Prado Coello. Porto, Fïgucirinhas.

FREUD, S. (1980) O problema cconômico do masoxpuismo. In. -. Obrras Complelas. Vol. XiX. Rio de Janciro, Inaago, p. 197-212.

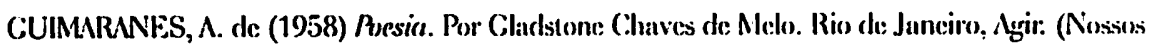
(Clássicos, 19).

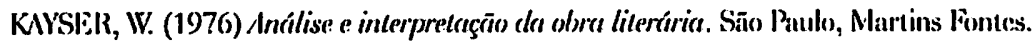

I API ANCI IF: \& PONTAI IS (1991) Kócrbulário cka psicanálise. São Paulo, Martins lơntes.

MLTOS, (). (1987) A melancolia de Ulisscs: a dialética do lluninismo e: o canto daıs serviats. In:

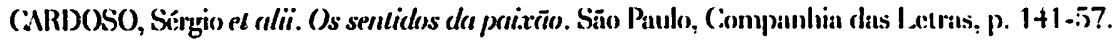

MOISl:́s, M. (1974) Dicionário de Lermos literrírios. São Paulo, Cullvix.

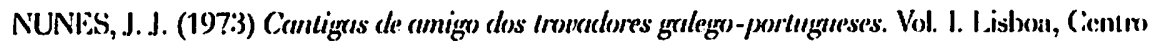
do Livro Brasilciro.

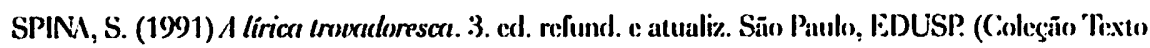
\& Arte).

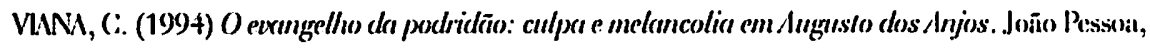
lidlitora Universitária/UPPPB. 